\title{
Multiple oncogenic viruses are present in human breast tissues before development of virus associated breast cancer
}

\author{
James S. Lawson ${ }^{1,2^{*}}$ and Wendy K. Glenn ${ }^{1}$
}

\begin{abstract}
Background: Multiple oncogenic viruses including, mouse mammary tumor virus, bovine leukemia virus, human papilloma virus, and Epstein Barr virus, have been identified as separate infectious pathogens in human breast cancer. Here we demonstrate that these four viruses may be present in normal and benign breast tissues 1 to 11 years before the development of same virus breast cancer in the same patients.
\end{abstract}

Methods: We combined the data we developed during investigations of the individual four oncogenic viruses and breast cancer. Patients who had benign breast biopsies 1-11 years prior to developing breast cancer were identified by pathology reports from a large Australian pathology service (Douglas Hanly Moir Pathology). Archival formalin fixed specimens from these patients were collected. The same archival specimens were used for (i) investigations of mouse mammary tumour virus (also known as human mammary tumour virus) conducted at the Icahn School of Medicine at Mount Sinai, New York and at the University of Pisa, Italy, (ii) bovine leukemia virus conducted at the University of California at Berkeley, (iii) human papilloma virus and Epstein Barr virus conducted at the University of New South Wales, Sydney, Australia.

Seventeen normal breast tissues from cosmetic breast surgery conducted on Australian patients were used as controls. These patients were younger than those with benign and later breast cancer.

Results: Standard and in situ polymerase chain reaction (PCR) methods were used to identify the four viruses. The detailed methods are outlined in the separate publications.: mouse mammary tumor virus, human papilloma virus and Epstein Barr virus (Infect Agent Cancer 12:1, 2017, PLoS One 12:e0179367, 2017, Front Oncol 5:277, 2015, PLoS One 7 : e48788, 2012).

Epstein Barr virus and human papilloma virus were identified in the same breast cancer cells by in situ PCR. Mouse mammary tumour virus was identified in 6 (24\%) of 25 benign breast specimens and in 9 (36\%) of 25 breast cancer specimens which subsequently developed in the same patients.

Bovine leukemia virus was identified in 18 (78\%) of 23 benign breast specimens and in 20 (91\%) of 22 subsequent breast cancers in the same patients.

High risk human papilloma viruses were identified in 13 (72\%) of 17 benign breast specimens and in 13 (76\%) of 17 subsequent breast cancers in the same patients.

Epstein Barr virus was not identified in any benign breast specimens but was identified in 3 (25\%) of 12 subsequent breast cancers in the same patients.

Mouse mammary tumour virus 3 (18\%), bovine leukemia virus 6 (35\%), high risk human papilloma virus 3 (18\%) and Epstein Barr virus 5 (29\%) were identified in 17 normal control breast specimens.

(Continued on next page)

\footnotetext{
*Correspondence: james.lawson@unsw.edu.au

${ }^{1}$ School of Biotechnology and Biomolecular Sciences, University of New

South Wales, Sydney 2052, Australia

${ }^{2}$ School of BABS, University of NSW, Sydney, NSW 2110, Australia
} 
(Continued from previous page)

Conclusions: These findings add to the evidence that multiple oncogenic viruses have potential roles in human breast cancer. This is an important observation because evidence of prior infection before the development of disease is a key criterion when assessing causation.

Keywords: Mouse mammary tumor virus, Bovine leukemia virus, Human papilloma virus, Epstein Barr virus, Benign breast, Breast cancer

\section{Background}

Over 40 different viruses have been identified by whole genome sequencing in invasive breast cancers [1]. However, only four of these viruses are known to have potential oncogenic influences in breast cancer. These are mouse mammary tumor virus (MMTV), bovine leukemia virus (BLV), human papilloma virus (HPV) and Epstein Barr virus (EBV). Each of these four oncogenic viruses have been studied as separate infectious pathogens in benign breast tissues and subsequent breast cancer in the same patients (2-5). We have previously demonstrated that MMTV, HPV and EBV may be present in the same breast cancer cells [5].These findings have been recently confirmed in a study of MMTV, HPV and EBV in breast cancer among Pakistan women [6]. MMTV, BLV, high risk for cancer HPVs and EBV have an oncogenic capacity in either animals (MMTV and BLV), or humans (HPVs and EBV), [7-10].

\section{Mouse mammary tumour-like virus (MMTV)}

The potential role of MMTV in human breast cancer has been intensively studied for over 50 years. Recent findings have confirmed the likely role of MMTV in human breast cancer. The evidence is as follows: (i) a meta-analysis of 22 studies concluded that the identification of MMTVlike gene sequences in breast cancer tissues, was associated with a 15 fold increase in breast cancer [11], (ii) the near complete proviral structure of MMTV-like virus has been identified in human breast tumours [12], (iii) MMTV proteins indirectly transform human breast epithelial cells [13], (iv) MMTV viral proteins have been identified in human breast cancer [14], (vi) Wnt-1 oncogene expression is significantly higher in MMTV-like positive compared to MMTV-like negative breast cancer specimens, which parallels high Wnt-1 expression in MMTV positive mouse mammary tumours [15], (vii) MMTV can infect human breast epithelial cells and randomly integrate its' genomic information [16], (viii) there is a progressive increase in the prevalence of MMTV-like viral sequences in normal breast (nil), normal adjacent to breast cancer (19\%), breast hyperplasia (27\%) and ductal carcinoma in situ (82\%) [17], (x) at a microscopic level, the morphology of MMTV-like positive human breast cancer is very similar to the morphology of MMTV positive mouse mammary tumours [15], (xi)
MMTV-like viral sequences have been identified in milk from healthy lactating women and increased prevalence in milk from women at high risk for breast cancer [18], (xii) MMTV-like viral sequences have been identified in the saliva of $27 \%$ of normal children, $11 \%$ of healthy adults and $57 \%$ of adults with breast cancer, which is suggestive of a human to human viral transmission [19], (xiii) MMTV-like viral sequences have been identified in breast cancers which developed in a father, mother and daughter of the same family which is suggestive of an infectious condition [20]. In a recent study MMTV-like virus was identified in benign breast tissues before the development 3 to 10 years later of MMTV positive breast cancer in the same patients [2].

Overall, this evidence is compatible with MMTV having similar influences in both human breast cancer and mouse mammary tumours.

\section{Bovine leukemia virus (BLV)}

BLV is a retrovirus which causes leukemia in up to $5 \%$ of BLV infected cattle [3]. BLV infected cattle are found world wide and up to $85 \%$ of US dairy cattle are infected [3]. Milk of dairy cows frequently contains a leukogenic virus [21]. The evidence for a role of BLV in human breast cancer is as follows: (i) BLV gene sequences and proteins have been identified in human breast tissues in US, Columbian and Australian women $[3,22]$. (ii) In a US based study of 114 breast cancer cases and 112 normal controls, the prevalence of BLV was 59\% in breast tumours as compared to $29 \%$ of controls $(p=0.004)$ [23], (iii) in a Colombia based study of 43 breast cancer cases and 53 non breast cancer controls the prevalence of BLV was $36 \%$ in breast tumours and $45 \%$ of controls [22], (iv) in a recent Australian study BLV was present in $74 \%$ of benign breast tissues 3-10 years before the development of BLV positive breast cancer in the same women [3].

Contrary to the positive identification of BLV in these studies, BLV was not identified by PCR techniques in breast cancers in Chinese patients nor by whole genome sequencing in European patients [24, 25]. The study on Chinese women has been shown to be flawed [3]. The reason for the negative outcome based on whole genome sequencing is not clear. A plausible reason is that whole genome sequencing techniques are 
not as sensitive as amplification techniques such as PCR [26].

BLV and BLV-infected cells are present in colostrum and milk of most infected cows. This is the most likely means of transmission from cows to humans. There is a striking geographical correlation between the incidence of breast cancer and milk consumption [3]. Women with lactose intolerance and who have a low consumption of milk and dairy products, have a significantly lower risk of breast cancer than other women and other family members [27]. In addition there are significant correlations between the consumption of beef and breast cancer [28].

This evidence is limited, but overall, these data are compatible with a role for BLV in human breast cancer.

\section{High risk human papilloma virus (HPV)}

There is substantial evidence which indicates a potential role for high risk HPVs in breast cancer. This evidence includes (i) meta-analyses of 22 studies conducted in a wide range of countries indicate that infection with high risk HPVs is associated with an increased risk of breast cancer with an overall odds ratio of 5.4, there are marked differences between countries in the prevalence of high risk HPVs in breast cancer [29], (ii) recent studies in the United Kingdom and Spain also indicate an increased risk of breast cancer associated with HPV infection [30, 31], the risk differs according to HPV type, with 5.7 fold higher risk for HPV 16, 3.6 fold increase for HPV 33 and 3.0 fold increase for HPV 18 [29], (iii) HPVs immortalize and transform human mammary epithelial cells [32], (iii) HPV E6 and E7 oncoproteins have been identified in breast cancers, however, there is a low level of transcription of these oncoproteins which suggests that any influences of HPVs in breast cancer are likely to be indirect [4, 33], (iv) high risk HPVs have been identified in the SK-BR-3 breast cancer cell line [34], (v) HPV type 16 E6 and E7 oncoproteins convert non-invasive and nonmetastatic breast cancer cells to invasive and metastatic phenotypes [35], (vi) HPV-positive breast cancer is more common in young as compared to older women, an observation which is compatible with sexual transmission of HPV among sexually active younger women [36], (vi) HPV positive koilocytes have been identified in breast cancers [37], (vii) the prevalence of HPV positive breast cancer is higher in women with prior HPV associated cervical cancer [38], (viii) high risk HPV gene sequences are present in benign breast tissues prior to the development 3 to 10 years later of same HPV type positive breast cancers [4].

The prevalence of breast cancer is not increased in immunocompromised patients with AIDS or organ transplants [39]. This is in contrast to the 5 fold increase in HPV associated cervical cancer in these patients [39]. The implication is that any oncogenic influences of viruses in breast cancer are indirect or there is a "hit and run" viral influence. There is evidence in support of both notions. HPVs appear to influence the cell cycle control enzyme APOBEC which leads to genomic instability and ultimately to breast cancer [40]. There is high HPV E7 oncoprotein expression in benign breast tissues and low HPV E7 expression in subsequent breast cancer which developed in the same patients [41].

These data are compatible with an indirect role for high risk HPVs in breast cancer.

\section{Epstein Barr virus (EBV)}

An association between EBV and breast cancer is likely. The evidence is as follows: (i) Various EBV genes have been identified by in situ hybridisation, immunohistochemistry, in situ PCR and by PCR in microdissected breast cancers in a wide range of countries [42]. The prevalence of EBVs in breast cancers varies from 0 to $100 \%$. The identification of EBV in normal and benign breast tissue controls are, with 2 exceptions, negative $[5,42]$. Many additional studies based on PCR of EBVs in breast cancer, are not valid because standard PCR techniques cannot distinguish between cancer cells and infiltrating lymphocytes, (ii) breast epithelial cells can be infected with EBV by cell to cell contact [43]. (iii) EBV infection predisposes breast epithelial cells to malignant transformation, [44], (iv) EBV is accepted as a major contributor to Hodgkin lymphoma and there are significant correlations between the incidence of Hodgkin lymphoma and breast cancer which suggests that EBV may also contribute to some breast cancers [45].

These observations are also compatible with an indirect role for EBV in breast cancer.

With respect to infectious agents and cancer, a key causal criteria is the presence of infectious agents prior to the development of cancer [46]. For this reason we have combined the data we developed during investigations of the individual four oncogenic viruses and breast cancer [2-5]. Here we show that multiple oncogenic viruses may be present in benign breast tissues prior to the development of the same virus positive invasive breast cancers in the same patients.

\section{Methods}

This project has formal ethics approval by the University of New South Wales, Sydney, Australia, Human Research Ethics Committee - number HREC HC11421. De-identified archival specimens were used in this study.

Approximately 4000 patient records from a large Australian pathology service (Douglas Hanly Moir Pathology) were reviewed to identify patients who had breast biopsies that included an initial benign breast specimen and a later breast cancer specimen. Forty one suitable patients were identified. Archival formalin fixed specimens from these patients were collected. The average age of the patients 
with benign breast conditions was 50.5 years and subsequent cancer 56.1 years. The same archival specimens were used for (i) investigations of mouse mammary tumour virus (also known as human mammary tumour virus) conducted at the Icahn School of Medicine at Mount Sinai, New York and at the University of Pisa, Italy, (ii) bovine leukemia virus conducted at the University of California at Berkeley,(iii) human papilloma virus and Epstein Barr virus conducted at the University of New South Wales, Sydney, Australia.

Seventeen normal breast tissues from cosmetic breast surgery conducted on Australian patients were used as controls. These patients were younger than those with benign and later breast cancer.

Standard and/or in situ polymerase chain reaction (PCR) methods were used to identify the four viruses. The detailed methods are outlined in the separate publications: mouse mammary tumor virus, human papilloma virus and Epstein Barr virus [2-5]. A summary of the methods used is as follows:

\section{Detection of mouse mammary tumour virus-like env sequences}

The DNA extraction and detection of MMTV-like env sequences were performed by PCR techniques as described by Wang et al. [47]. The primer sequences used in these PCR analyses include part of the MMTV env gene, which differs from human endogenous retrovirus 10 (HERV-K10). The same PCR techniques were used in both the Mount Sinai and University of Pisa laboratories with the exception of microdissection of the tumour tissues, that were analysed in the University of Pisa laboratory by fluorescence nested PCR.

\section{Detection of bovine leukemia virus sequences}

Both standard and in situ PCR was used to detect BLV DNA in the tissue samples [3]. The primer sequences, were from the tax region of the BLV genome. The specificity of these primers for BLV has previously been demonstrated by NCBI BLAST sequence alignments [23].

\section{Detection of high risk for cancer human papilloma virus gene sequences}

In situ PCR, semi-nested PCR, and real-time PCR plus whole genome sequencing were used for the detection of HPV [4]. All PCR products were sequenced to help identify any contamination. Although in situ PCR can produce false positive outcomes, use of this method can add to the validity of results based on semi-nested and real time PCR. The HPV PCR products from GP5 to Gp6 were sequenced to determine the HPV type. The HPV genotypes were identified by BLAST via the US National Center for Biotechnology Information.

\section{Detection of Epstein Barr gene sequences}

Both standard and nested PCR and in situ PCR techniques were used [5].

\section{Results}

The results are shown in Tables 1, 2 and 3. There was sufficient archival material to seek to identify the four target viruses in both benign breast tissues and subsequent breast cancers in the same patients in up to 27 of the 41 patients.

Bovine leukemia virus (BLV) was identified by in situ PCR in 18 (78\%) of 23 benign breast specimens and in 20 (91\%) of 22 subsequent breast cancers in the same patients. The identity of BLV was confirmed by sequencing the products of standard PCR. Because the prevalence of bovine leukemia virus is so high in both benign breast and later breast cancer cells (78\% of benign breast and $91 \%$ of breast cancer specimens), it is likely that this virus is colocated with other virus positive benign and breast cancer cells.

Mouse mammary tumour virus was identified in 6 (24\%) of 25 benign breast specimens and in 9 (36\%) of 25 breast cancer specimens which subsequently developed in the same patients.

High risk human papilloma viruses were identified in $13(72 \%)$ of 17 benign breast specimens and in 13 (76\%) of 17 subsequent breast cancers in the same patients.

Epstein Barr virus was identified in 3 (25\%) of 12 breast cancer specimens, but was not identified in any benign breast specimens from the same patients.

EBV and HPV were identified in the same breast cancer cells by in situ PCR. The images are shown in Fig. 1.

MMTV 3 (18\%), BLV 6 (35\%), high risk HPV 3 (18\%) and EBV 5 (29\%) were identified in 17 normal control breast specimens.

These data indicate that multiple oncogenic viruses may be present in both prior benign breast tissues and subsequent breast cancers that developed 1 to 11 years later in the same patients. In addition, these same viruses are present in a small proportion of normal breast tissues.

The numbers of patients and specimens are too small to justify a formal assessment of correlations between the presence of one or more of these viruses.

\section{Discussion}

In this study we have demonstrated the presence of four oncogenic viruses in benign breast tissues and the same viruses in subsequent breast cancers that developed 1 to 11 years later in the same patients. We have also shown that HPVs and EBV can be co-located in the same breast cancer cells.

Validity of the data in the current studies. PCR methods were used to identify the four oncogenic viruses, bovine leukemia virus, mouse mammary tumor virus, high risk 
Table 1 Multiple viruses human breast cancers

\begin{tabular}{|c|c|c|c|c|c|c|}
\hline Patient & Age & Diagnosis & BLV & MMTV & HPV & EBV \\
\hline \multirow[t]{2}{*}{1} & 36 & benign & pos & neg & neg & neg \\
\hline & 41 & Invasive dc & pos & neg & 18 & $n$ \\
\hline \multirow[t]{2}{*}{2} & 72 & benign & pos & neg & & \\
\hline & 75 & dcis & pos & neg & & \\
\hline \multirow[t]{2}{*}{3} & 33 & benign & pos & neg & $18 / 45$ & \\
\hline & 44 & Invasive dc & pos & neg & 18 & pos \\
\hline \multirow[t]{2}{*}{4} & 45 & benign & pos & pos & $16 / 18$ & \\
\hline & 46 & dcis & pos & pos & 18 & \\
\hline \multirow[t]{2}{*}{5} & 50 & benign & neg & pos & neg & \\
\hline & 60 & Invasive Ic & pos & pos & neg & ne \\
\hline \multirow[t]{2}{*}{6} & 62 & benign & pos & neg & 124 & $\mathrm{ne}$ \\
\hline & 66 & dcis & pos & neg & & ne \\
\hline \multirow[t]{2}{*}{7} & 47 & benign & pos & neg & neg & \\
\hline & 56 & Invasive dc & pos & neg & neg & \\
\hline \multirow[t]{2}{*}{8} & 49 & benign & neg & neg & & \\
\hline & 52 & Invasive dc & pos & neg & & \\
\hline \multirow[t]{2}{*}{9} & 46 & benign & pos & neg & 18 & \\
\hline & 53 & Invasive dc & pos & pos & 18 & \\
\hline \multirow[t]{2}{*}{10} & 48 & hyperplasia & pos & pos & 18 & \\
\hline & 52 & Invasive dc & pos & pos & neg & neg \\
\hline \multirow[t]{2}{*}{11} & 35 & benign & pos & neg & & \\
\hline & 46 & Invasive dc & neg & neg & & \\
\hline \multirow[t]{2}{*}{12} & 44 & benign & pos & neg & 18 & ne \\
\hline & 48 & Invasive dc & neg & neg & 18 & $\pi$ \\
\hline \multirow[t]{2}{*}{13} & 67 & hyperplasia & neg & neg & & \\
\hline & 75 & Invasive dc & & neg & & \\
\hline \multirow[t]{2}{*}{14} & 48 & benign & & neg & neg & \\
\hline & 54 & Invasive dc & & neg & neg & pos \\
\hline \multirow[t]{2}{*}{15} & 47 & benign & & & 18 & \\
\hline & 48 & Invasive dc & & & 18 & \\
\hline \multirow[t]{2}{*}{16} & 42 & benign & neg & neg & 18 & $\mathrm{ne}$ \\
\hline & 49 & Invasive dc & pos & pos & 18 & neg \\
\hline \multirow[t]{2}{*}{17} & 42 & benign & pos & neg & & \\
\hline & 48 & Invasive dc & pos & neg & & \\
\hline \multirow[t]{2}{*}{18} & 39 & benign & pos & neg & 18 & \\
\hline & 45 & Invasive Ic & pos & neg & 18 & \\
\hline \multirow[t]{2}{*}{19} & 54 & benign & pos & neg & & \\
\hline & 62 & dcis & pos & pos & 18 & \\
\hline \multirow[t]{2}{*}{20} & 65 & hyperplasia & pos & pos & & neg \\
\hline & 67 & Invasive dc & pos & neg & & \\
\hline \multirow[t]{2}{*}{21} & 39 & benign & neg & neg & neg & \\
\hline & 44 & dcis & pos & neg & neg & \\
\hline \multirow[t]{2}{*}{22} & 55 & benign & pos & neg & & \\
\hline & 62 & Invasive dc & pos & neg & & \\
\hline
\end{tabular}

Table 1 Multiple viruses human breast cancers (Continued)

\begin{tabular}{lllllll}
\hline Patient & Age & Diagnosis & BLV & MMTV & HPV & EBV \\
\hline 23 & 59 & benign & & & 18 & \\
& 65 & Invasive lc & & & 18 & \\
24 & 37 & benign & pos & neg & neg & \\
& 39 & Invasive dc & pos & neg & $16 / 18$ & \\
25 & 39 & benign & & pos & 18 & \\
& 42 & dcis & & pos & 18 & neg \\
26 & 48 & benign & pos & pos & $16 / 18$ & \\
& 54 & Invasive dc & pos & pos & $16 / 18$ & pos \\
27 & 63 & benign & pos & neg & & \\
& 67 & Invasive dc & pos & pos & 18 & neg
\end{tabular}

Dcis ductal carcinoma in situ, Invasive dc invasive ductal carcinoma, Invasive Ic invasive lobular carcinoma, Pos positive, Neg negative

Gaps in the table are due to inadequate tissues or absence of beta globin

human papilloma viruses and Epstein Barr virus. PCR analyses are notoriously liable to contamination leading to false positive outcomes. Not so well known is the problem of false negative outcomes when PCR methods are used to identify low concentrations of retroviruses. This latter issue has been considered in detail by Vinner et al. [26]. Several different approaches were made to overcome these problems. With respect to bovine leukemia virus in situ PCR methods were used. As shown in Fig. 1, this method has the advantage of distinguishing between breast cancer and other cells. The identity of BLV was confirmed by the sequencing of the PCR products and comparisons with standard reference sequences. With respect to mouse mammary tumour virus, standard PCR methods were used on the same specimens in two independent laboratories. In the Pisa laboratories laser microdissection techniques were used to carefully exclude stromal and lymphocyte cells from the breast tissues. In the Mount Sinai, New York, laboratories PCR methods were used to exclude contamination by mouse mitochondrial sequences. However it should be noted that the results of PCR analyses of the same breast specimens has some differences between the two laboratories. This is a reflection of the difficulty of consistent detection of low concentrations of retroviruses. With respect to high risk human papilloma viruses, the identification was by in situ PCR, standard PCR and

Table 2 Multiple oncogenic viruses in benign breast and same virus in subsequent breast cancer in the same patients

\begin{tabular}{lll}
\hline & $\begin{array}{l}\text { Benign breast } \\
\text { biopsy tissues }\end{array}$ & $\begin{array}{l}\text { Subsequent breast } \\
\text { cancer same patient }\end{array}$ \\
\hline Mouse mammary tumor virus & $6 / 25(24 \%)$ & $9 / 25(36 \%)$ \\
Bovine leukemia virus & $18 / 23(78 \%)$ & $20 / 22(91 \%)$ \\
High risk human papilloma virus & $13 / 18(72 \%)$ & $13 / 17(76 \%)$ \\
Epstein Barr virus & $0 / 4(0 \%)$ & $3 / 12(25 \%)$ \\
\hline
\end{tabular}


Table 3 MMTV, BLV, HPV and EBV sequences in normal breast tissues

\begin{tabular}{llllll}
\hline Patient & Age & MMTV & BLV & HPV & EBV \\
\hline 1 & 22 & neg & pos & neg & neg \\
2 & 24 & neg & pos & neg & neg \\
3 & 26 & neg & neg & neg & neg \\
4 & 46 & pos & pos & pos & neg \\
5 & 49 & neg & neg & neg & neg \\
6 & 26 & neg & pos & neg & neg \\
7 & 46 & pos & pos & neg & pos \\
8 & 27 & neg & neg & neg & neg \\
9 & 55 & neg & pos & neg & neg \\
10 & 61 & neg & neg & neg & neg \\
11 & 28 & pos & neg & pos & pos \\
12 & 28 & neg & neg & neg & neg \\
13 & 19 & neg & neg & neg & pos \\
14 & 55 & neg & neg & neg & pos \\
15 & 33 & neg & neg & pos & \\
16 & 19 & neg & neg & neg & pos \\
17 & 55 & neg & neg & neg & neg \\
\hline Normal breast tissues were from cosmetic surgery & &
\end{tabular}

immunohistochemistry, each of which added to the validity of the outcomes. There were variations in the sequences which is an indication that contamination was unlikely. With respect to Epstein Barr virus the identification was also by in situ PCR, standard PCR and immunohistochemistry, each of which added to the validity of the outcomes.

There is substantial, but not conclusive, evidence that each of these viruses may have oncogenic influences in breast cancer. This is despite the fact that in immunocompromised patients such as those with organ transplant immunosuppression or human immunodeficiency virus, there is no increased prevalence of virus positive breast cancer [39]. It has been argued that, if for example MMTVs or HPVs had a causal role in breast cancer, an increase in expected prevalence should occur as there is an up to 5 fold increase in HPV associated cervical cancer among these patients. The explanation with respect to MMTV is that intact lymphocytes are required to transmit the virus to target organs [7]. Lymphocytes, as part of the immune system, are compromised in immunosuppressed patients. With respect to HPVs, their oncogenic influences may be indirect and not subject to the immune system. HPVs increase the activity of the cell cycle enzyme APOBEC3B which in turn causes genomic instability and increased risk of breast and other cancers [40].

There are a number of different types of breast cancer. Historically these types have been classified mainly by their histological characteristics and include ductal carcinoma in situ, invasive ductal carcinoma, invasive lobular carcinoma and special types including tubular carcinoma, cribriform carcinoma, mucinous carcinoma, medullary carcinoma, micropapillary carcinoma, neuro-endocrine carcinoma plus other rare types [48]. More recently
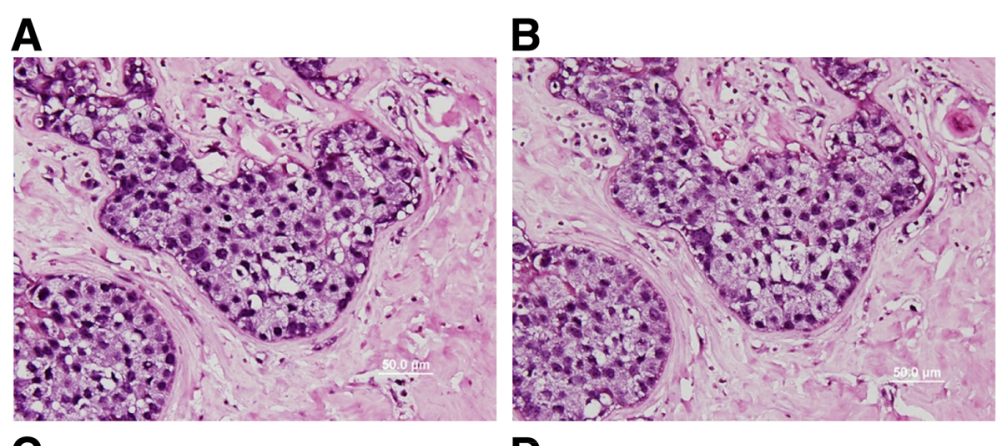

C
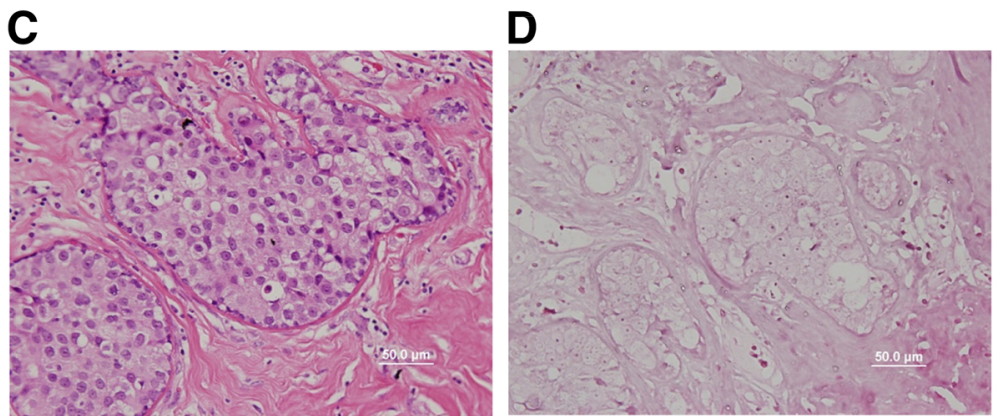

Fig. 1 EBV and HPV nucleotide sequences shown by in situ PCR in the nuclei of the same breast cancer cells (ductal carcinoma in situ). a EBV in breast cancer cell nuclei. b HPV in breast cancer cell nuclei. $\mathbf{c}$ Haematoxylin and eosin (H \& E) stain. d Negative controls. No PCR primers 
invasive breast cancers have been classified by their molecular characteristics and include luminal, basal like and HER 2 status [49]. It is possible that different viruses are associated with different types of breast cancer. For example mouse mammary tumour virus positive invasive human breast cancers frequently have the same histological characteristics as mouse mammary virus positive mouse mammary tumours. These tumours are very similar to many breast ductal carcinoma in situ breast cancers and special breast cancer types such as medullary carcinoma, adenoid cystic carcinoma and neuroendocrine carcinoma $[50,51]$.

Several of these four oncoviruses are co-located in breast cancer cells and may collaborate with each other to increase their oncogenic potential. We have shown in this current study that HPVs and EBV can be co-located in breast cancer cells. We have previously shown that MMTV gene sequences may also be co-located with HPVs and EBVs in the same breast cancer cells [5]. Because the prevalence of bovine leukemia virus is high in both benign breast and later breast cancer cells (78\% of benign breast and $91 \%$ of breast cancer specimens), it is likely that this virus is also co-located with other virus positive benign and breast cancer cells. However there is no direct evidence of such co-location. Nor is there evidence that such co-location of these viruses leads to increased oncogenic influences in breast cancer. On the other hand, in studies of women with breast cancer in Syria, it was shown that a co-prevalence of EBVs and high risk HPVs in $32 \%$ of the breast tumours was associated with high grade invasive ductal breast cancers [52]. In addition there is preliminary experimental evidence that HPVs and EBVs collaborate [53]. It is not known how different viruses co-operate to induce cancer. There are current research activities aimed at the elucidation of this issue with specific reference to HPV and EBV [54].

\section{Conclusions}

The identification of multiple oncogenic viruses in benign breast tissues prior to the subsequent development of same virus breast cancer in the same patients is an important observation. This is because evidence of prior infection before the development of disease is a key criterion when assessing causation. These findings add to the evidence that oncogenic viruses have potential roles in human breast cancer.

\footnotetext{
Acknowledgements

The identification and collection of the specimens was by Rosemary Clay and Warick Delprado of Douglass Hanly Moir Pathology, Sydney, Australia. The analyses of these specimens was conducted in the laboratories of Beatriz Pogo, Icahn School of Medicine at Mount Sinai, New York; Gertrude Buehring, University of California at Berkeley; Chiara Mazzanti, Fondazione Pisana per la Scienza, Pisa, Italy; and Noel Whitaker, University of New South Wales, Sydney, Australia.
}

Funding

There was no funding for this project.

Availability of data and materials

Detailed data is available in Table 1.

\section{Authors' contributions}

JSL initiated this project, developed the concepts and drafted the manuscript. WKG supervised and conducted relevant laboratory analyses, reviewed and analysed the data, participated in the design of the project and helped draft the manuscript. Both authors read and approved the final manuscript.

\section{Ethics approval and consent to participate}

This project has formal ethics approval by the University of New South Wales Human Research Ethics Committee - number HREC HC11421.

\section{Consent for publication}

Not applicable.

\section{Competing interests}

Neither of the authors have any financial or intellectual competing interest.

\section{Publisher's Note}

Springer Nature remains neutral with regard to jurisdictional claims in published maps and institutional affiliations.

Received: 27 July 2017 Accepted: 9 October 2017

Published online: 16 October 2017

\section{References}

1. Larsson Lab. Larssonlab.org/tcga-viruses/report_BRCA.php.

2. Nartey T, Mazzanti CM, Melana S, Glenn WK, Bevilacqua G, Holland JF, et al. Mouse mammary tumor-like virus (MMTV) is present in human breast tissue before development of virally associated breast cancer. Infect Agent Cancer. 2017;12:1.

3. Buehring GC, Shen H, Schwartz DA, Lawson JS. Bovine leukemia virus linked to breast cancer in Australian women and identified before breast cancer development. PLoS One. 2017;12:e0179367.

4. Lawson JS, Glenn WK, Salyakina D, Delprado W, Clay R, Antonsson A, et al. Human Papilloma Viruses and Breast Cancer. Front Oncol. 2015;5:277.

5. Glenn WK, Heng B, Delprado W, lacopetta B, Whitaker NJ, Lawson JS. Epstein-Barr virus, human papillomavirus and mouse mammary tumour virus as multiple viruses in breast cancer. PLoS One. 2012;7:e48788.

6. Naushad W, Surriya O, Sadia H. Prevalence of EBV, HPV and MMTV in Pakistani breast cancer patients: a possible etiological role of viruses in breast cancer. Infect Genet Evol. 2017; doi:10.1016/..meegid.2017.07.010.

7. Dudley JP, Golovkina TV, Ross SR. Lessons learned from mouse mammary tumor virus in animal models. ILAR J. 2016:57:12-23.

8. Schwartz I, Levy D. Pathobiology of bovine leukemia virus. Vet Res. 1994;25:521-36.

9. zur Hausen H. Papillomaviruses and cancer: from basic studies to clinical application. Nat Rev Cancer. 2002;2:342-50.

10. Young LS, Rickinson AB. Epstein-Barr virus: 40 years on. Nat Rev Cancer. 2004:4:757-68.

11. Wang F, Hou J, Shen Q, Yue Y, Xie F, Wang X, et al. Mouse mammary tumor virus-like virus infection and the risk of human breast cancer: a meta-analysis. Am J Transl Res. 2014;6:248-66.

12. Melana SM, Nepomnaschy I, Sakalian M, Abbott A, Hasa J, Holland JF, et al. Characterization of viral particles isolated from primary cultures of human breast cancer cells. Cancer Res. 2007;67:8960-5.

13. Katz E, Lareef MH, Rassa JC, Grande SM, King LB, Russo J, et al. MMTV Env encodes an ITAM responsible for transformation of mammary epithelial cells in three-dimensional culture. J Exp Med. 2005;201:431-9.

14. Melana SM, Nepomnaschy I, Hasa J, Djougarian A, Djougarian A, Holland JF, et al. Detection of human mammary tumor virus proteins in human breast cancer cells. J Virol Methods. 2010;163:157-61.

15. Lawson JS, Glenn WK, Salmons B, Ye Y, Heng B, Moody P, et al. Mouse mammary tumor virus-like sequences in human breast cancer. Cancer Res. 2010;70:3576-85.

16. Indik S, Günzburg WH, Salmons B, Rouault F. 60-7. Mouse mammary tumor virus infects human cells. Cancer Res. 2005;65:6651-9. 
17. Mazzanti CM, Al Hamad M, Fanelli G, Scatena C, Zammarchi F, Zavaglia K, et al. A mouse mammary tumor virus env-like exogenous sequence is strictly related to progression of human sporadic breast carcinoma. Am J Pathol. 2011;179:2083-90.

18. Nartey T, Moran H, Marin T, Arcaro KF, Anderton DL, Etkind P, et al. Human Mammary Tumor Virus (HMTV) sequences in human milk. Infect Agent Cancer. 2014;9:20.

19. Mazzanti CM, Lessi F, Armogida I, Zavaglia K, Franceschi S, Al Hamad M, et al. Human saliva as route of inter-human infection for mouse mammary tumor virus. Oncotarget. 2015;6:18355-63.

20. Etkind PR, Stewart AF, Wiernik PH. Mouse mammary tumor virus (MMTV)-like DNA sequences in the breast tumors of father, mother, and daughter. Infect Agent Cancer. 2008;3:2.

21. Ferrer JF, Kenyon SJ, Gupta P. Milk of dairy cows frequently contains a leukogenic virus. Science. 1981:213(4511):1014-6.

22. Mesa G, Ulloa JC, Uribe AM, Gutierre MF. Bovine leukemia virus gene segment detected in human breast tissue. Open Journal of Medical Microbiology. 2013;3:84-90.

23. Buehring GC, Shen HM, Jensen HM, Jin DL, Hudes M, Block G. Exposure to Bovine Leukemia Virus Is Associated with Breast Cancer: A Case-Control Study. PLoS One. 2015;10:e0134304.

24. Zhang R, Jiang J, Sun W, Zhang J, Huang K, Gu X, et al. Lack of association between bovine leukemia virus and breast cancer in Chinese patients. Breast Cancer Res. 2016;18:101

25. Gillet NA, Willems $L$. Whole genome sequencing of 51 breast cancers reveals that tumors are devoid of bovine leukemia virus DNA. Retrovirology. 2016;13:75.

26. Vinner L, Mourier T, Friis-Nielsen J, Gniadecki R, Dybkaer K, Rosenberg J, et al. Investigation of Human Cancers for Retrovirus by Low-Stringency Target Enrichment and High-Throughput Sequencing. Sci Rep. 2015;5:13201.

27. Ji J, Sundquist J, Sundquist K. Lactose intolerance and risk of lung, breast and ovarian cancers: aetiological clues from a population-based study in Sweden. Br J Cancer. 2015;112:149-52.

28. zur Hausen $\mathrm{H}$, de Villiers EM. Dairy cattle serum and milk factors contributing to the risk of colon and breast cancers. Int J Cancer. 2015;137:959-67.

29. Bae JM, Kim EH. Human papillomavirus infection and risk of breast cancer: a meta-analysis of case-control studies. Infect Agent Cancer. 2016;11:14.

30. Delgado-García S, Martínez-Escoriza JC, Alba A, Martín-Bayón TA, BallesterGaliana H, Peiró G, et al. Presence of human papillomavirus DNA in breast cancer: a Spanish case-control study. BMC Cancer. 2017;17:320.

31. Salman NA, Davies G, Majidy F, Shakir F, Akinrinade H, Perumal D, et al. Association of high risk human papillomavirus and breast cancer: A UK based Study. Sci Rep. 2017;7:43591.

32. Dimri G, Band H, Band V. Mammary epithelial cell transformation: insights from cell culture and mouse models. Breast Cancer Res. 2005;7:171-9.

33. Wang D, Fu L, Shah W, Zhang J, Yan Y, Ge X, et al. Presence of high risk HPV DNA but indolent transcription of E6/E7 oncogenes in invasive ductal carcinoma of breast. Pathol Res Pract. 2016;212:1151-6.

34. Yan C, Teng ZP, Chen YX, Shen DH, Li JT, Zeng Y. Viral Etiology Relationship between Human Papillomavirus and Human Breast Cancer and Target of Gene Therapy. Biomed Environ Sci. 2016;29:331-9.

35. Yasmeen A, Bismar TA, Kandouz M, Foulkes WD, Desprez PY, Al Moustafa AE. E6/E7 of HPV type 16 promotes cell invasion and metastasis of human breast cancer cells. Cell Cycle. 2007;6:2038-42.

36. Lawson JS, Glenn WK, Whitaker NJ. Breast cancer, human papilloma virus and sexual activities. Br J Cancer. 2008;98:510-1.

37. Lawson JS, Glenn WK, Heng B, Ye Y, Tran B, Lutze-Mann L, et al. Koilocytes indicate a role for human papilloma virus in breast cancer. Br J Cancer. 2009;101:1351-6.

38. Lawson JS, Glenn WK, Salyakina D, Clay R, Delprado W, Cheerala B, et al. Human Papilloma Virus Identification in Breast Cancer Patients with Previous Cervical Neoplasia. Front Oncol. 2016;5:298.

39. Grulich AE, Vajdic CM. The epidemiology of cancers in human immunodeficiency virus infection and after organ transplantation. Semin Oncol. 2015:42:247-57.

40. Ohba K, Ichiyama K, Yajima M, Gemma N, Nikaido M, Wu Q, et al. Vivo and in vitro studies suggest a possible involvement of HPV infection in the early stage of breast carcinogenesis via APOBEC3B induction. PLoS One. 2014:9:e97787.

41. Ngan C, Lawson JS, Clay R, Delprado W, Whitaker NJ, Glenn WK. Early Human Papilloma Virus (HPV) Oncogenic Influences in Breast Cancer. Breast Cancer (Auckl). 2015;9:93-7.
42. Richardson AK, Currie MJ, Robinson BA, Morrin H, Phung Y, Pearson JF, et al. Cytomegalovirus and Epstein-Barr virus in breast cancer. PLoS One. 2015;10:e0118989.

43. Speck P, Longnecker R. Infection of breast epithelial cells with Epstein-Barr virus via cell-to-cell contact. J Natl Cancer Inst. 2000;92:1849-51.

44. Hu H, Luo ML, Desmedt C, Nabavi S, Yadegarynia S, Hong A, et al. EpsteinBarr Virus Infection of Mammary Epithelial Cells Promotes Malignant Transformation. EBioMedicine. 2016;9:148-60.

45. Yasui Y, Potter JD, Stanford JL, Rossing MA, Winget MD, et al. Breast cancer risk and "delayed" primary Epstein-Barr virus infection. Cancer Epidemiol Biomark Prev. 2001;10:9-16.

46. Hill AB. The environment and disease: association or causation? Proc R Soc Med. 1965:58:295-330

47. Wang Y, Holland JF, Bleiweiss IJ, Melana S, Liu X, Pelisson I, et al. Detection of mammary tumor virus env gene-like sequences in human breast cancer. Cancer Res. 1995;55:5173-9.

48. O'Malley \& Pinder. Breast pathology. Philadelphia: Churchill Livingstone; 2006.

49. Weigelt B, Horlings HM, Kreike B, Hayes MM, Hauptmann M, Wessels LF, de Jong D, Van de Vijver MJ, veer Van't LJ, Peterse JL. Refinement of breast cancer classification by molecular characterization of histological special types. J Pathol. 2008;216(2):141-50.

50. Lawson JS, Tran DD, Carpenter E, Ford CE, Rawlinson WD, Whitaker NJ, Delprado W. Presence of mouse mammary tumour-like virus gene sequences may be associated with morphology of specific human breast cancer. J Clin Pathol. 2006;59(12):1287-92.

51. Lawson JS, Ngan CC, Glenn WK, Tran DD. Mouse mammary tumour virus (MMTV) and human breast cancer with neuroendocrine differentiation. Infect Agent Cancer. 2017;12:24.

52. Al Moustafa AE, Al-Antary N, Aboulkassim T, Akil N, Batist G, Yasmeen A. Coprevalence of Epstein-Barr virus and high-risk human papillomaviruses in Syrian women with breast cancer. Hum Vaccin Immunother. 2016;12:1936-9.

53. Cameron J. HPV and EBV collaboration. Trieste: International Centre for Genetic Engineering and Biotechnology. DNA tumour virus meeting abstracts; 2011

54. Deng Z, Uehara T, Maeda H, Hasegawa M, Matayoshi S, Kiyuna A, Agena S, Pan X, Zhang C, Yamashita Y, Xie M, Suzuki M. Epstein-Barr virus and human papillomavirus infections and genotype distribution in head and neck cancers. PLoS One. 2014;9(11):e113702.

\section{Submit your next manuscript to BioMed Central and we will help you at every step:}

- We accept pre-submission inquiries

- Our selector tool helps you to find the most relevant journal

- We provide round the clock customer support

- Convenient online submission

- Thorough peer review

- Inclusion in PubMed and all major indexing services

- Maximum visibility for your research

Submit your manuscript at www.biomedcentral.com/submit 